\title{
The Andermann Syndrome: Agenesis of the Corpus Callosum Associated with Mental Retardation and Progressive Sensorimotor Neuronopathy
}

\author{
Albert Larbrisseau, Michel Vanasse, Pierre Brochu and Gaétan Jasmin
}

ABSTRACT: Andermann et al. described in 1972 an autosomal recessive inherited syndrome which associates agenesis of the corpus callosum, mental deficiency, and a peripheral motor deficit. We had the opportunity to study in detail 15 patients affected by this syndrome. As in the cases previously reported, the families of these children all originated from Charlevoix County and the Saguenay-Lac St-Jean area in the Province of Quebec.

Clinically, these patients have a characteristic facies and moderate mental retardation associated with a progressive motor neuropathy leading to loss of ambulation by adolescence and progressive scoliosis. In 13 of these 15 patients, neuroradiological investigation has shown either total or partial agenesis of the corpus callosum. In every patient in whom these tests were done, sensory nerve action potentials were absent and motor nerve conduction velocities reduced. We also found neurogenic abnormalities both on EMG and neuromuscular biopsies. These abnormalities are similar to those described in Friedreich's ataxia and in hereditary motor and sensory neuropathy type II, although in our patients the motor deficit is much more severe than in these diseases.

The pathogenesis of the peripheral nervous system involvement is still unknown since there have so far been no autopsy studies of this syndrome.

RÉSUMÉ: Andermann et coll. ont identifié en 1972 un syndrome héréditaire à transmission autosomale récessive associant une agénésie du corps calleux à une déficience intellectuelle et à une atteinte motrice périphérique. Nous avons eu l'occasion d'étudier en détail 15 patients atteints de ce syndrome. Tout comme dans les cas rapportés précédemment, les familles de ces enfants étaient toutes originaires du comté de Charlevoix et de la région du Saguenay-Lac St-Jean (province de Québec).

Sur le plan clinique, ces patients présentent un faciès caractéristique et une déficience intellectuelle associés à une polyneuropathie motrice évolutive, entraînant l'apparition d'une scoliose et la perte de la marche au plus tard à l'adolescence. Chez 13 des 15 patients, l'investigation neuro-radiologique a montré une agénésie partielle ou totale du corps calleux. Chez tous les patients chez qui ces examens ont été faits, nous avons noté une abolition des potentiels évoqués sensitifs, une diminution des vitesses de conduction motrice et des signes d'atteinte neurogène tant à l'EMG qu'à la biopsie neuromusculaire. Ces anomalies sont semblables à celles que l'on retrouve dans l'ataxie de Friedreich et dans la polyneuropathie sensitivo-motrice héréditaire de type II, quoique l'atteinte motrice clinique soit beaucoup plus sévère chez nos patients.

La pathogénie des lésions du système nerveux périphérique nous est encore inconnue car jusqu'à maintenant aucune autopsie n'a été pratiquée chez ces patients.

Can. J. Neurol. Sci. 1984; 11:257-261

Agenesis of the corpus callosum has been found to be associated with a wide variety of other congenital malformations (Parrish et al., 1979). Andermann et al. $(1972,1977,1978,1981)$ have recognized a new autosomal recessive syndrome consisting of agenesis of the corpus callosum and a progressive sensorimotor neuronopathy. All the families originated from Charlevoix County in the Province of Quebec; most of them have migrated to the Saguenay-Lac St-Jean region. We had the opportunity to study 15 patients in 14 sibships presenting such a syndrome. All their parents come from these regions, where a high degree of consanguinity existed. In this report we describe their clinical, electrophysiological and pathologic findings.

From the Service de Neurologie. Département de Pédiatrie. Hôpital Sainte-Justine, Université de Montréal, (Drs. Larbrisseau and Vanasse) and the Département de Pathologie, Hópital Sainte-Justine. Université de Montréal, (Drs. Brochu and Jasmin)

Reccived July 14, 1983. Accepted in revised form January 8, 1984

Reprint requests to: Dr. Albert Larbrisseau. Service de Neurologie, Hôpital Sainte-Justine. 3175 Côte Ste-Catherine. Montréal, Québec H3T 1C5 


\section{Clinicai, Presentation}

Detailed data from history, physical examination and laboratory findings of the patients studied are given in Tables 1, 2 and 3. A distinct clinical picture emerges from a review of these clinical findings. History revealed an unremarkable neonatal period in all patients. Asphyxia or hypotonia at birth were never mentioned. Around 4-6 months of age, the parents become aware of some degree of hypotonia and slowing of motor development. Delays in motor milestones then become obvious; the child sits without support around age 11 to 12 months and stands only a little past his second birthday. Some have started walking with aid and braces between age 4 and 8 years but many have never walked by themselves. After some progress has been attained, slowly progressive motor disability supervenes. By the age of 10 to 13 , they are either confined to a wheelchair or bedridden.

Physical examination reveals striking dysmorphic features in the majority of cases: elongated facies, hypertelorism, high arched palate, hypoplastic maxilla and large angle of the mandible. In addition to these features, many patients have a slight bilateral palpebral ptosis and always some degree of facial diplegia which give them a distinct appearance. Nystagmus and mild ophthalmoplegia are more frequently encountered in older children. Visual disturbance, optic atrophy or sensorineural deafness were not seen.

Early in the course of the disease, diffuse hypotonia and absence of deep tendon reflexes are found. Frequently, foot deformities such as equinovarus or metatarsus are also noted. From 2 to 4 years of age, amyotrophy becomes prominent, particularly in distal muscles of the lower extremities. This is associated with a marked decrease in muscle strength. A few years later, signs of progressive scoliosis become apparent. Because of the patients' limited mental capacities, sensory involvement is difficult to assess. In older children, some decreased perception of touch and pinprick is found in a glove and stocking distribution in the distal part of the extremities. Psychological evaluation reveals moderate mental retardation (IQ: 45-60) in the majority of cases.

\section{LABORATORY FINDINGS}

Cerebrospinal fluid (CSF) was obtained in 10 patients. In all but 2 , it showed an increase in total protein from 64 to $87 \mathrm{mg} \%$. CSF immunoglobulins were assayed in 5 cases; in all the immunoglobulin (IgG) was increased or at the upper level of normal ( 2.5 to $6.5 \mathrm{mg} / \mathrm{dl})$. This probably reflects some radicular involvement and the increased IgG could represent some ongoing, active process. Respiratory function tests were performed only in the oldest patient who was also the most severely affected; he had a $97^{\circ}$ dorso-lumbar scoliosis. Vital capacity was $22 \%$ of normal; his functional residual capacity was $48 \%$ and total capacity (TLC) $34 \%$. These results were indicative of a severe restrictive syndrome.

Cranial computed tomography (CT) was performed in 12 patients and pneumoencephalography (PEG) in 6. The typical findings of agenesis of the corpus callosum were found in 10 (Fig. 1); partial agenesis was found in 3 (as demonstrated in each case by both PEG and CT). In 2 cases, no abnormal findings could be found on CT. These 2 patients, however, had the typical clinical, EMG and biopsy features of the disease; their parents were from the Saguenay-Lac St-Jean region.

In every patient, sensory and motor nerve conduction velocities were done both in upper and lower extremities. At least two sensory and two motor nerves were studied. EMG was performed in the lower extremities and included a study of the extensor digitorum brevis and tibialis anterior muscles.

The electrophysiologic findings were virtually identical in every patient and included: 1) absence of sensory action potentials, 2) a slight reduction of motor nerve conduction velocity with values from 35 to $40 \mathrm{~m} / \mathrm{sec}$, 3) signs of denervation and reinnervation (Vanasse et al., 1980) in the distal muscles of the lower extremities, consisting of various combinations of abnormal activity at rest (fibrillations and pseudomyotonic discharges), increased duration or amplitude of the motor unit potentials, increased polyphasic potentials and reduction of the interference pattern. Although all these signs were not all present in every patient, EMG showed clearly neurogenic abnormalities in all cases.

\section{Pathologic Findings}

\section{Methods}

A muscle biopsy from the gastrocnemius was obtained in 8 patients. These biopsies were frozen in isopentane precooled in liquid nitrogen. The sections were cut at $10 \mu \mathrm{m}$ and stained with hemalun-phloxine-Saffron, myofibrillar AtPase preincubated at $\mathrm{pH}$ 9.4,4.6 and 4.3, menadione-linked alpha glycerophosphate

\begin{tabular}{|c|c|c|c|c|c|c|c|c|c|c|c|c|c|c|c|}
\hline Patients & 1 & 2 & 3 & 4 & 5 & 6 & 7 & 8 & 9 & 10 & 11 & 12 & 13 & 14 & 15 \\
\hline Age at last examination (years) & 19 & 15 & 13 & 10 & 9 & 5 & 5 & 4 & 4 & $31 / 2$ & 3 & 2 & $11 / 2$ & 1 & $1 / 2$ \\
\hline$\overline{\operatorname{Sex}}$ & $\mathbf{M}$ & $F$ & $\overrightarrow{\mathrm{M}}$ & $\mathbf{M}$ & $\bar{F}$ & $\mathbf{M}$ & $\mathbf{M}$ & $F$ & $\mathbf{M}$ & $\mathbf{F}$ & $F$ & $M$ & $\mathbf{M}$ & $F$ & $\mathbf{M}$ \\
\hline Affected sib or relative & + & - & - & - & - & - & $+*$ & - & - & + & + & - & - & - & + \\
\hline Sits alone (months) & 24 & 24 & 24 & - & 36 & 36 & 16 & 14 & - & 24 & 24 & - & - & - & - \\
\hline Walks with aid (years) & 5 & 7 & 8 & - & 4 & - & $11 / 2$ & 3 & - & - & - & - & - & - & - \\
\hline Wheel chair or bedridden & + & + & + & + & - & + & - & - & + & + & + & - & - & - & - \\
\hline
\end{tabular}

\footnotetext{
* Case 11
} 
deshydrogenase, NADH tetrazolium reductase, acid phosphatase, methylgreen pyronine, oil red $\mathbf{0}$ and Gomori Trichrome. Histographic analyses were done on all biopsies.

Combined biopsies of the sural nerve and of the gastrocnemius muscle were performed on the right lower limb. Small fragments were fixed in $2.5 \%$ phosphate buffered glutaraldehyde and postfixed in $2 \%$ buffered osmium tetroxide. After rinsing, all specimens were routinely dehydrated and embedded in Epon-812. Sections ( $1 \mu \mathrm{m}$ thick) were stained with toluidine blue or p-phenylenediamine for light microscopy. Thin sections were stained with uranyl acetate and lead citrate and examined in a Philips 300 electron microscope.

\section{Light microscopy}

Angular fibers were found in all biopsies, being quite numerous in seven. Small group atrophy was noted in seven biopsies and large group atrophy in three, the latter representing the oldest patients. In the youngest patient's biopsy, the angular fibers were uniformly distributed in the muscle bundles without forming group atrophy. There was type grouping in all biopsies, marked in six and slight in two. Three biopsies showed predominance of type 2 fibers, one of these with type I fiber deficiency. The two oldest patients exhibited more than $5 \%$ internal nuclei $(11 \%$ and $20 \%$ respectively) with pyknotic nuclear clumps.

Rare basophilic fibers were seen in two biopsies. Necrotic fibers, split fibers, moth-eaten fibers and whorled fibers were seen in only one biopsy. No target fibers were detected. Three biopsies showed slight fibrosis and moderate to marked interstitial fat infiltration.

Histographic analyses revealed atrophy of type 1 fibers in seven biopsies, type $2 \mathrm{~A}$ fibers in six, and type $2 \mathrm{~B}$ fibers in five. No biopsy showed type 1 fiber hypertrophy. Type $2 A$ fiber

Table 2: Physical findings in 15 patients with the Andermann Syndrome

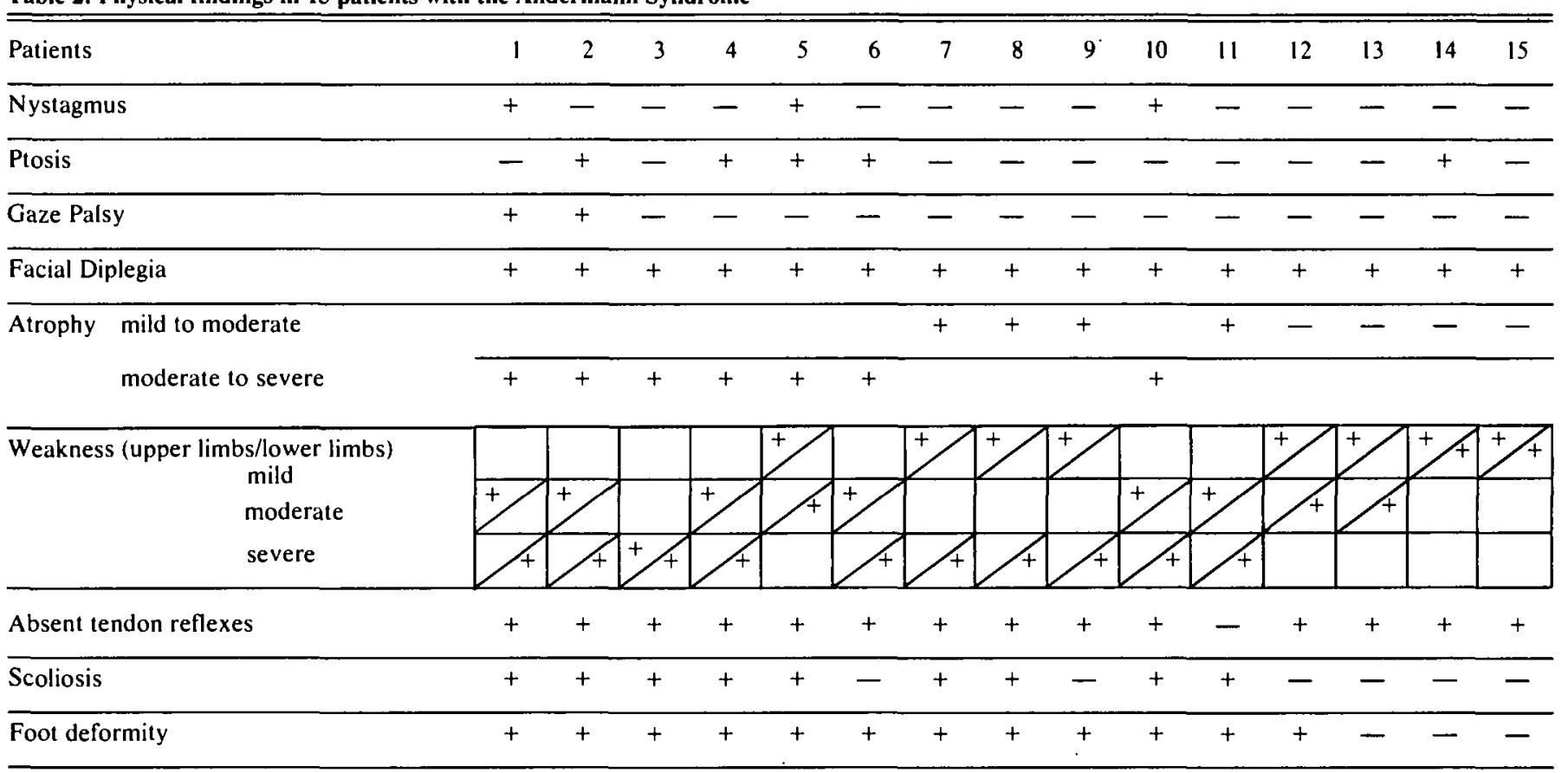

\begin{tabular}{|c|c|c|c|c|c|c|c|c|c|c|c|c|c|c|c|}
\hline Agenesis Corpus Collosum & - & \pm & + & + & + & \pm & - & \pm & - & + & + & + & + & + & + \\
\hline $\begin{array}{l}\text { Abnormal electro-physiological } \\
\text { studies }\end{array}$ & + & + & + & + & + & + & + & + & + & + & + & + & + & + & + \\
\hline $\begin{array}{r}\text { CSF protein }(\mathrm{MG} \%) \\
(\mathrm{N}:<55)\end{array}$ & ND & 67 & 40 & 64 & 70 & 84 & 49 & 69 & 69 & ND & 87 & ND & ND & ND & 80 \\
\hline Moderate mental retardation & + & + & + & + & + & + & + & + & + & + & + & + & $?$ & $?$ & $?$ \\
\hline
\end{tabular}

$\pm \quad$ Partial agenesis

ND Not done

? Formal psychological evaluation not done. 


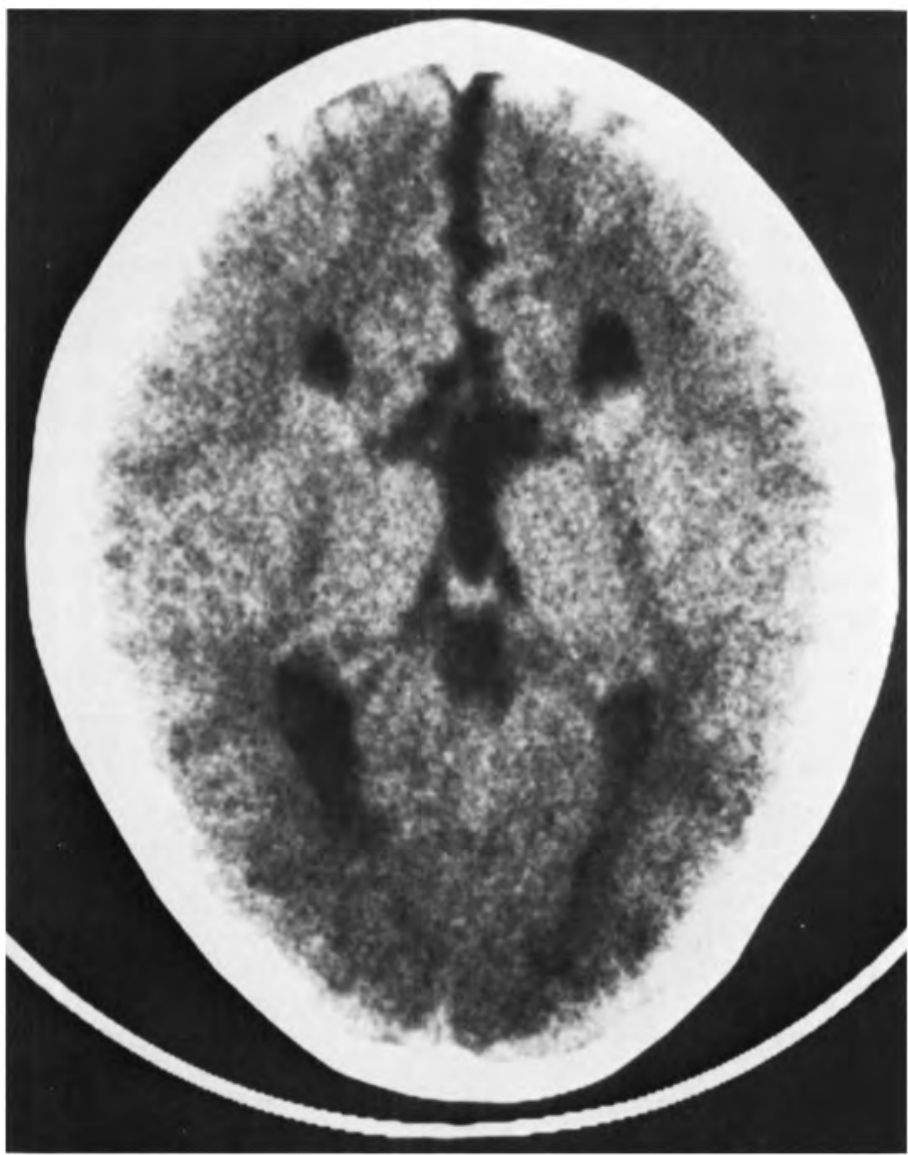

Figure I - Ct-Scan showing absence of the genu of the corpus callosum resulting in a highly situated third ventricle and eccentric position of the lateral ventricles.

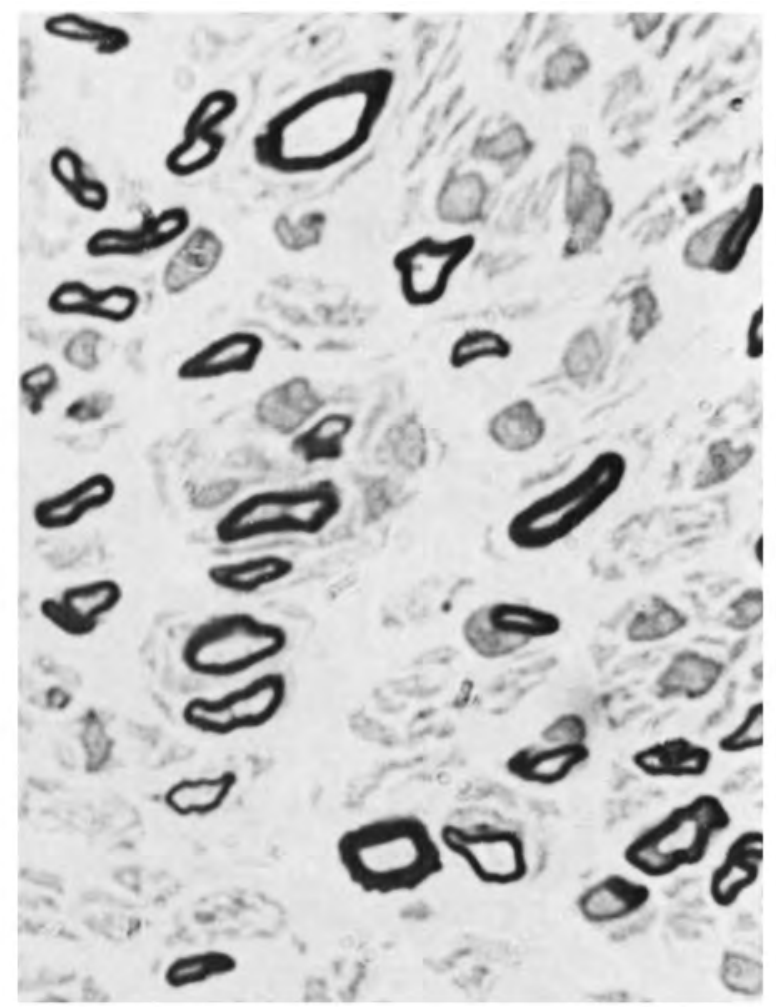

Figure 2 - Semithin transverse section of the sural nerve showing Schwann cell proliferation around myelinated fibers. Toluidine blue XI,200. hypertrophy was noted in one biopsy and type $2 \mathrm{~B}$ fiber hypertrophy in two biopsies. These three patients with hypertrophic fibers were the youngest. A typical twin-peaked histogram was drawn from each biopsy, generally for all three fiber subtypes. In summary, the biopsies showed histologic lesions of chronic denervation, with angular fibers and type grouping. They usually exhibited atrophy of all three fiber subtypes, with very rare occurrence of hypertrophy. By light microscopy, the most prominent feature in cross-sections of the sural nerve was the clustering of myelinated or unmyelinated fibers within a dense fibrous endoneurial matrix (Fig. 2).

\section{Electron microscopy}

Ultrastructurally, the aggregated fibers disclosed myelinoaxonal involutive changes with a tendency to form onion bulbs (Fig. 3). Stacks of unmyelinated fibers appeared edematous while demyelinated axons were loaded with dense granules. Schwann cells enclosed in their cytoplasm ill-defined vesicles with myelin fragments and a variable amount of glycogen granules. Some axons were partly denuded or filled with neurotubules and occasionally showed large mitochondria with curvilinear structures. More severely altered axons were crowded with numerous dark inclusions deriving from fragmented myelin and occasionally some long-spacing collagen. The overall pathologic picture is very suggestive of a chronic demyelinating neuropathy.

Myofibrillary degenerative changes on the other hand were rather characteristic of a denervation process. The pathologic changes included all features of slowly progressive degeneration with fibrillar disarray, thickened $Z$ lines reminiscent of nemaline rods, filamentous bodies, collection of triads and laminated concentric lamellae enclosed in large glycogen pockets underneath the sarcolemma. In these areas as well as in the intermyofibrillar spaces, mitochondria were rarefied. They often showed in their matrix amorphous or crystalline inclusions.

\section{Discussion}

Familial occurrence of agenesis of the corpus callosum is rare. Thus far, 7 reports of such families have been published (Lynn et al., 1980). In most, the condition has been transmitted by autosomal recessive inheritance. One family had X-linked inheritance (Menkes et al., 1964) and one had an autosomal dominant inheritance (Lynn et al., 1980).

Parrish et al. (1979) have made an extensive review of associated anomalies discovered at autopsy. They found anomalies of nearly every structure of the central nervous system (CNS), the most frequent being gyral dysplasia and heterotopias, hypoplasia of olfactory tracts or lobes and of the cerebellar vermis, meningeal abnormalities and widespread dysraphic manifestations. Nonnervous system anomalies were also frequently encountered. The most common were peculiar facies with ocular abnormalities, micrognathia, hypertelorism, and cleft lip or palate. Various musculoskeletal, cardiovascular and genitourinary malformations were also frequently noted.

The single most frequently associated CNS anomaly consisted of pyramidal tract changes: asymmetry, hypoplasia of the pyramids, and absent or incomplete decussation. There is no mention of abnormal findings in the lower motor neuron or dorsal root ganglion.

One of the better characterized entities with agenesis of the corpus callosum is the Aicardi syndrome. It consists of seizures, 


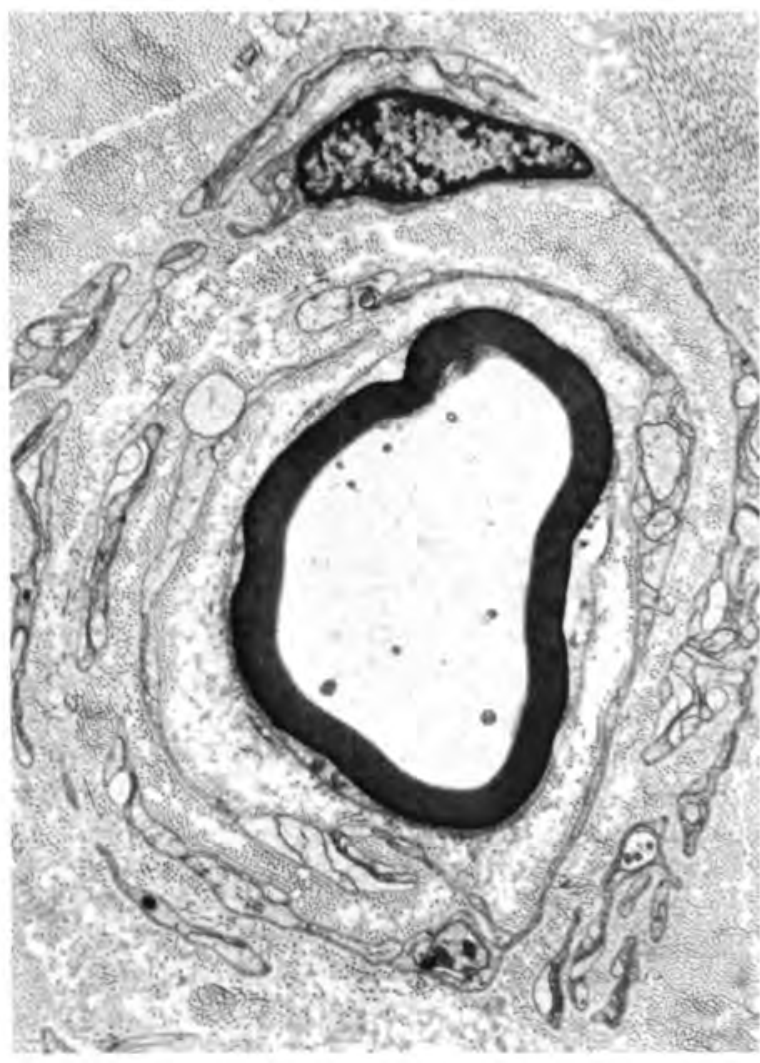

Figure 3 - Electron micrograph of an onion bulbformation. Note the revolving Schwann cell processes around a myelinated nerve fiber (reduced from X3,730).

especially spasms in flexion, chorioretinal lacunae, mental subnormality and vertebral and other abnormalities. (De Jong et al., 1976). Only girls are affected. Although there has been some speculation that this syndrome may be due to an $\mathrm{X}$ chromosome dominant inheritance with manifestation in the heterozygotes and with a male lethal factor (De Jong et al., 1976), a genetic etiology is hypothetical. Furthermore, no familial recurrence is known (Aicardi, 1980).

Our cases, which are similar in all respects to the ones first described by Andermann et al. (1972, 1977, 1978, 1981) stand out as a unique entity with distinct clinical features. No previous cases of agenesis of the corpus callosum have been found to be associated with lower motor neuron or peripheral nervous system involvement. Andermann et al. (1972) originally ascribed the slowly progressive weakness to anterior horn cell disease as has also been suggested more recently by Giroud and Langevin (1982). However, neurophysiological and histological findings in peripheral nerves and muscles, as well as the increased CSF protein and immunoprotein, are more indicative of peripheral nerve involvement. Although the clinical picture is much more severe in our patients, electromyographic and nerve conduction study findings are identical to those described in Friedreich's ataxia (Peyronnard et al., 1976), and in hereditary sensory and motor neuropathy type II (Dyck, 1975). In both these conditions, histological and pathological findings have suggested that nerve involvement is secondary to neuronal atrophy and degeneration of peripheral sensory and motor neurons (Dyck, 1975; McLeod, 1971). It is quite likely that a similar abnormality will be found in our patients. However, so far no autopsy has been performed in any of these cases. Until then, the exact pathogenesis of the peripheral involvement in this condition eludes us.

The unique association of distinct clinical features assures the specificity of this syndrome. Even when the agenesis of the corpus callosum could not be found on PEG or CT, no other entity could account for the unique combination of mental retardation, involvement of some cranial nerves, and a very specific neuromuscular disorder. The ethnic background of these families also helps identify this condition. The recognition of such a syndrome is important in view of the genetic counselling which can now be provided. Andermann et al. (1978), after studying over 100 cases and establishing the family pedigree, have been able to trace most of them back to a common ancestral couple from France who married in Quebec City in 1657. When specifically looked for, consanguinity could always be established. All these families thus studied show a clear pattern of autosomal recessive inheritance.

\section{REFERENCES}

Aicardi J (1980) Aicardi syndrome in a male infant. J. Ped. 97: 1040. Andermann F, Andermann E, Joubert M, Karpati G, Carpenter S, Melançon D (1972) Familial agenesis of the corpus callosum with anterior horn cell disease: a syndrome of mental retardation, areflexia and paraparesis. Trans. Amer. Neurot. Ass. 97: 242-244.

Andermann E, Andermann F, Carpenter S, Karpati G, Eisen A. Melançon D, Bergeron J (1977) Familial agenesis of the corpus callosum with spinal cord involvement: a new autosomal recessive syndrome originating in Charlevoix County. In: New syndromes, edited by Daniel Bergsine and Brian Lowry. Birth Defects, original article series, Vol. XIII, No. 38, 232-233.

Andermann E, Andermann F, Bergeron D, Nagy R, Bergeron J (1978) The autosomal recessive syndrome of agenesis of the corpus callosum and sensorimotor neuronopathy: a review of over 100 cases from Charlevoix County and the Saguenay-Lac St-Jean area of Quebec. IVth International Congress of Neuromuscular Disorders, Montreal, abstract no. 515 .

Andermann E (1981) Sensorimotor neuronopathy with agenesis of the corpus callosum. In: Handbook of Clinical Neurology. Vol. 42: Neurogenetic Directory Part I. N.C. Myriam Teopoulos, Ed. NorthHolland Publishing Co., Amsterdam. pp. 100-103.

Dyck PJ (1975) Inherited neuronal degeneration and atrophy affecting peripheral motor, sensory and autonomic neurons. In: Peripheral Neuropathy. Vol. 11, Dyck PJ, Thomas PK, and Lambert EH eds, W.B. Saunders Co., Philadelphia, pp. 825-867.

De Jong JGY, Delleman JW, Houben M, Manschot WA, de Minjer A, Mol J, Sloof J (1976) Agenesis of the corpus callosum, infantile spasms, ocular anomalies (Aicardi's syndrome). Neurology 26: 1152-1158.

Giroud M, Langevin P (1982) Agénésie du corps calleux et atteinte de la corne antérieure de la moelle, une affection rare. Pédiatrie 37: 113-117.

Lynn RB, Buchanan DC, Fenichel GM, Freeman FR (1980) Agenesis of the corpus callosum. Arch. Neurol. 37: 444-445.

McLeod JG (1971) An electrophysiological and pathological study of peripheral nerves in Friedreich's ataxia. J. Neurol. Sci. 12: 333-349.

Menkes JH, Philippart M, Clark DB (1964) Hereditary partial agenesis of the corpus callosum. Arch. Neurol. 11: 198-208.

Parrish ML, Roesmann U, Levinsohn MW (1979) Agenesis of the corpus callosum: a study of the frequency of associated malformations. Ann. Neurol. 6: 349-354.

Peyronnard JM, Lapointe L, Bouchard JP, Lamontagne A, Lemieux B, Barbeau A (1976) Nerve conduction studies and electromyography in Friedreich's ataxia. Can. J. Neurol. Sci. 3: 313-317.

Vanasse M, Lemay R, Brochu P (1982) Apport de l'électromyographie au diagnostic différentiel de l'hypotonie infantile. Union Méd. Cana. 111: 347-352. 